Physical Disabilities: Education and Related Services, 2014, 33(2), 36-52. doi: 10.14434/pders.v33i2.13071

(C) Division for Physical, Health and Multiple Disabilities

\title{
PDERS
}

ISSN: 2372-451X

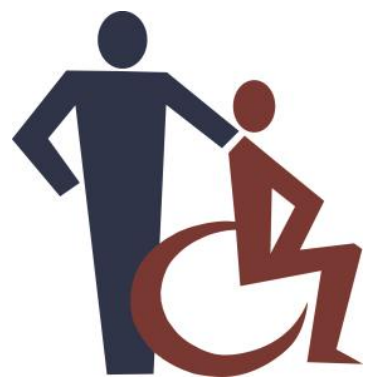

http://scholarworks.iu.edu/journals/index.php/pders/index

Article

\section{THERE'S NO PLACE LIKE HOME: TRAINING, PRACTICES, AND PERCEPTIONS OF HOMEBOUND SERVICES}

\author{
Constance C. Petit \\ California State University, Bakersfield \\ Philip P. Patterson \\ University of Alaska, Fairbanks
}

\begin{abstract}
Homebound services involve the delivery of special education in settings other than school sites. Such settings typically include students' homes or hospitals. Most often associated with early childhood special education and with students who are medically or physically fragile, homebound services can also be for those in need of interim alternative educational settings (IAES). Although homebound services have been available to some students with disabilities for more than 50 years, little research exists on that delivery model. This study investigated the training, practices and perceptions of service providers who work in homebound settings. Data from a self-administered survey of a national sample were analyzed. Key findings included: a widespread lack of training for professionals who delivered homebound services; an absence of school district or agency policies or procedure concerning the delivery of such services; and statistically significantly higher perceptions of self-efficacy by those who did receive training.
\end{abstract}

Keywords: homebound instruction; home/hospital; home-based intervention; IAES 


\section{Introduction}

There are more than 6.5 million students in the United States who receive special education services. A small percentage of those students (2.2\%) receive services in settings other than on public school campuses (Data Accountability Center [DAC], 2012). One optional delivery method to receive services is through homebound instruction. Not to be confused with homeschooling where parents assume the responsibility for the instruction of their children, homebound instruction can be described as publically supported special education services generally provided on a case-by-case basis, in a setting other than on a school site (Petit, 2013). While this service delivery model most often occurs in a student's home, it can additionally take place in a hospital setting or at a neutral location such as a public library (Patterson \& Petit, 2008; Patterson \& Tullis, 2007). Homebound services can also be referred to as home/hospital services, home visits, or home-based intervention.

Although homebound instruction has been a recognized alternative education approach since the 1950s (Florida State Department of Education, 1983), it has not been a frequent topic of K-12 special educational research (Petit, 2013). When mentioned in the literature, it often is on a peripheral rather than a primary basis (Searle, Askins, \& Bleyer, 2003; Shaw, Glasner, Stern, Sferdenschi, \& McCabe, 2010; Shaw \& McCabe, 2008). One exception to this phenomenon is in the field of Early Childhood Special Education, where homebound services are more readily addressed (Cook, Sparks, Rosetti, \& Osselaer, 2008; Keilty, 2008; Prior \& Gerard, 2007). Another exception includes the treatment of chronically ill children who are more commonly provided with homebound instruction (Clay, Cortina, Harper, Cocco, \& Drotar, 2004; Hamlet, Gergar, \& Schaefer, 2011; Journal of School Health, 2003; Shaw \& McCabe, 2008). There are many unknown factors related to the provision of homebound services, especially on a national scale. Such factors include accurate data on the frequency of homebound services, populations receiving such services, the availability of training and direction for administering homebound services, and the perceptions of personal and pedagogical effectiveness experienced by the service providers. Furthermore, the absence or lack of research and literature in the field may well extend to other written documents. Hamlet et al. (2011) speculated that even guidelines and written policies governing homebound instruction are not always available to service providers and administrators.

One critical consideration of educating students with special needs should be identifying improvements in the delivery of instruction and related services. Homebound services are legally recognized placement alternatives; they are identified on the continuum of service options, which are addressed within the Individuals with Disabilities Education Improvement Act (IDEIA) of 2004 (U.S. Department of Education, 2013). An absence of research or guidelines addressing a service delivery approach does not excuse a lack of quality or effectiveness as a special education function. Neglecting the delivery approach or using a substandard service model not only jeopardizes students' learning, but could also result in litigation (Patterson \& Petit, 2008). 


\section{The Context of Homebound Instruction}

Homebound instruction can be a traditional alternative placement option to on-campus services (DAC, 2012; Special Education \& Rehabilitative Services, 2007). It is often associated with early childhood special education and with students who are physically or medically fragile (Cook et al., 2008; Journal of School Health, 2003). It can also be an interim alternative education setting (IAES; Telzrow, 2001). IAESs are temporary placements (not exceeding 45 days), which allow students to receive educational services outside of their intended placements. Typically, such placements are for students in special education who are demonstrating major behavioral problems including drug or weapon possession, or for those exhibiting serious injurious behavior. Besides homebound settings, Bear, Quinn, and Burkholder (2001) list IAES as "schools within-a-school, intervention resource rooms, in-school suspension rooms, alternative classrooms, [and] mental health treatment facilities" (p. 7). These settings enable local education agencies (LEAs) to conduct further assessment, protecting the safety of all students, while still providing educational services (U.S. Department of Education, 2013).

The provision of homebound services to students with disabilities is determined by multidisciplinary teams and documented in Individual Education Programs (IEP) or Individual Family Service Plans (IFSP). The LEA is then responsible for providing appropriate instruction and related services that meet the legal requirements for the use of educational settings (Etscheidt, 2006). In selecting homebound services as a delivery method, IEP and IFSP team members should consider the restrictive nature of homebound services. Because of the potential for limited interaction with peers, homebound instruction is often seen as one of the most restrictive educational settings (Patterson \& Tullis, 2007). Another consideration is the assurance that students receiving homebound services have access to the general education curriculum (Bradley, 2007).

The designation of homebound services is a decision of IEP or IFSP teams. The nature and impact of the student's disability may affect the amount of time for which homebound instruction is provided. The extent of homebound instruction appears to fall in one of three categories: short-term (American Academy of Pediatrics, 2000; Bradley, 2007; Macciomei \& Ruben, 1989), transition or interim (Etscheidt, 2006; Searle et al., 2003; Shaw \& McCabe, 2008; Telzrow, 2001) and long-term (American Academy of Pediatrics, 2000; Boreson, 1994; Scarborough et al., 2004; Shaw \& McCabe, 2008). Depending upon the needs of individual students, services could include academic instruction, speech and language therapy, physical therapy, and occupational therapy. Homebound services are not limited to those provided by special education teachers but could also include related services (Patterson \& Petit, 2006).

Determining actual services related to homebound instruction can be difficult to interpret when examining data. According to the Digest of Educational Statistics (National Center for Educational Statistics, 2012) approximately $1 / 2$ of $1 \%$ of students, ages 6 to 21 , with categorical disabilities received homebound instruction from 1989 through 2010. If accurate, this statistic indicates that homebound services are relatively uncommon. Data on specific student disability populations who received homebound services is available for years 2008 to 2010. Those disability groups receiving homebound instruction at rates equal to or greater than $1 \%$ of the total special education student population included students with emotional disturbances, orthopedic 
impairments, other health impairments, deaf-blindness, multiple disabilities, and traumatic brain injury (National Center for Educational Statistics, 2012).

While the general policies and procedures of special education are determined by legislation, Lustig (2009) reported that there is a lack of "explicit federal statutory or regulatory guidelines on the appropriate use of homebound placements" (p. 5). Therefore states follow available federal regulations when establishing special education practices but also utilize a degree of autonomy for program development centered on their specific populations and needs. When not implicitly decreed by a state, districts may rely on their own interpretations for delivery, while in some instances, the courts interpret the guidelines. This individuality in developing specific policies and practices (or not) may be a factor in procedural variations and conflicts between different states and school districts (Lustig, 2009). The lack of explicit guidelines creates the potential for a wide range of conflicting placement and delivery practices. This is especially problematic in the field of special education where legal challenges abound. Katsiyannis, Yell, and Bradley (2001) indicated that, "perhaps no other area of educational law... has been more highly litigated than the education of students with disabilities" (p. 326).

One potential area of variation is within the rate, frequency, and duration of homebound services, however, this has not been nationally studied. The North Carolina Association for the Education of Chronically Ill Children (NCAECIC; 2009) polled southern states and determined that weekly instruction was frequently the requirement, but there was a wide range in the number of weekly instructional hours provided. Responses from Florida, Louisiana, South Carolina and Virginia suggested that four to ten instructional hours per week were determined by the grade level of the student.

Individual state's guidelines should indicate the appropriate type of certification required to provide homebound instruction (Lustig, 2009). The majority of service providers are teachers but speech and language pathologists, paraprofessionals, and physical or occupational therapists can provide services (Patterson \& Petit, 2006). However, service providers may inadvertently be underprepared to deliver homebound instruction. LEAs, who generally determine how educators are chosen to provide homebound instruction, may base their decisions on seniority, economy, or other factors rather than levels of preparation or competence (Patterson \& Petit, 2008). "Once selected, service providers may have little direction with regards to delivering or documenting instruction, collecting appropriate data and collaborating with the classroom teacher or parents" (Petit, 2013, p.4).

There is a potential that the use of homebound instruction could increase as a result of provisions within the reauthorization of IDEIA in 2004. In the latest version of this federal law, criteria for placing students in IAESs were expanded. Even before this reauthorization, Katsiyannis and Smith (2003) noted an apparent increase in the use of IAES. With the expanded criteria of IDEIA 2004 comes the potential increase in use, however, the practices concerning homebound instruction may not have experienced a change or improvement in the way they are delivered. One example includes site or program administrators who may be unfamiliar with the practices associated with IAES (Telzrow, 2001) and may therefore be ill prepared to supervise or evaluate the delivery of homebound services. 


\section{Purpose of the Study}

The purpose of this study was to examine several aspects of homebound instruction with specific regard to those who provide such instruction and their perceptions of this service model. The frequency, rate, and format of services along with an examination into the levels of preparation and training service providers possessed when delivering homebound instruction was conducted. The perceptions service providers held regarding the delivery model of homebound instruction for students with disabilities were investigated, and finally, the perceived effectiveness of this model by service providers who deliver homebound instruction was gauged.

\section{Methods}

The design of this research study was quantitative using a self-administered survey dispensed to a national sample of potential homebound service providers. The survey was created as a onetime data collection instrument. It was distributed in two formats: hard-copy and electronic.

\section{Participants}

The survey was constructed to collect data from educators and/or specialists who had provided or were currently providing educational support to students with disabilities in a homebound instructional setting. Members from two national professional organizations were selected as potential participants based on their probability of providing homebound instruction. The Division of Physical, Health and Multiple Disabilities, a subset of the Council for Exceptional Children (CEC), was the largest group with 400 members at the time of this research. The mailing list was procured following the guidelines from CEC. These members and potential respondents received the research survey in the mail. At the time of this study, CEC's protocol did not allow for the use of email addresses of its members.

The second professional organization used for this study was the Association for the Education of Children with Medical Needs (AECMN). This group of 84 members strives to support service providers of homebound instruction to students who have medical needs. These members received the survey electronically via email using the organization's protocol for the use of member contact.

\section{Instrumentation}

Data collection was accomplished using a survey constructed to examine the common practices associated with homebound instruction sessions such as frequency and duration, along with the attitudes and perceptions of service providers. The survey investigated the training or preparation service providers received and asked participants to indicate the types of degrees, certifications, or licenses as well as the number of years of experience they possessed. Categorical scales were used to evaluate these types of responses while summated rating scales were used for the examination of perceptions and attitudes (Johnson \& Christensen, 2008).

The printed version of the survey followed a booklet format using both sides of legal-sized paper which reduced the appearance of size with the intent of producing higher response rates 
(Krathwohl, 2009). Related topics were grouped (Dillman, Smyth, \& Christian, 2009) using headings in both the printed and electronic versions (Krathwohl, 2009). The rating scale sections included five possible participant responses ranging from Strongly Disagree to Strongly Agree. The electronic version was constructed using SurveyMonkey; participants received an email with weblink access to the survey.

Validity and reliability of the survey was established using a combination of safeguards. The survey in draft form was reviewed by university colleagues familiar with homebound instruction and survey design. Revisions were made based on feedback and suggestions. Next, an expert panel of special educators with a combination of 30 years of experience was interviewed after completing the survey. Additional revisions were incorporated based on their recommendations. Finally, individual prompts in the survey were tested for reliability or consistency using Chronbach's alpha.

\section{Data Collection}

The approach for data collection followed the suggested practices standard to the use of a survey as a research instrument. Participants initially received a pre-notice postcard or email message (Dillman et al., 2009). A cover letter detailing the research purpose accompanied the selfadministered questionnaires (Krathwohl, 2009) which were delivered one week after the prenotice and included a stamped, self-addressed return envelope. Two weeks later, a reminder notice was sent to the participant pool. Those who received the mailed version of the survey also received a small monetary incentive $(\$ 1.00)$.

The overall returned response rate for the 400 mailed surveys was $45 \%$ while the overall returned response rate for the 84 electronic versions was $46.4 \%$. The sum of useable surveys collected by both methods was 192 . These 192 respondents provided information on several key components of the research such as preparation to deliver homebound services and the availability of guidelines for delivering homebound instruction but not all of the 192 respondents were homebound service providers. Of that sum, 92 indicated that they were service providers for homebound instruction. There were 22 surveys returned as undeliverable which accounted for an additional $5.5 \%$ of the 400 mailed surveys.

\section{Results}

Data analysis was accomplished using descriptive and inferential statistics. Frequency tables represented the descriptive portion. An independent $t$-test was conducted to test the hypothesis regarding a statistically significant difference of the perceptions associated with model and personal effectiveness while multivariate analysis of variance (MANOVA) was used to analyze the inferential statistics examining the extent, if any, of differences of the individual constructs of model effectiveness and personal effectiveness.

\section{Demographic Information of Sample}

The majority of the respondents were female $(n=173)$ between the ages of 50 and $59(n=46)$ who resided in the South $(n=58)$ and had between 6 and 15 years of teaching experience $(n=$ 
51). Most were special educators $(n=88)$ but a significant group indicated they possessed both general and special education certification $(n=59)$. A smaller group of specialists and related service providers $(n=12)$ participated as well. Large school districts were the most represented by the respondents $(n=56)$. Refer to Table 1 for complete demographic characteristics of participants.

Table 1

Demographic Characteristics of Participants

\begin{tabular}{|c|c|c|c|c|}
\hline \multirow[b]{2}{*}{ Characteristic } & \multicolumn{2}{|c|}{$\begin{array}{l}\text { All Respondents } \\
\quad(n=192)\end{array}$} & \multicolumn{2}{|c|}{$\begin{array}{l}\text { Service Providers } \\
(n=92)\end{array}$} \\
\hline & $n$ & $\%$ & $n$ & $\%$ \\
\hline \multicolumn{5}{|l|}{$\overline{\text { Gender }}$} \\
\hline Male & 18 & 9.4 & 7 & 7.6 \\
\hline Female & 173 & 90.1 & 85 & 92.4 \\
\hline \multicolumn{5}{|l|}{ Age (years) } \\
\hline $25-29$ & 17 & 8.8 & 6 & 6.5 \\
\hline $30-39$ & 32 & 16.7 & 18 & 19.6 \\
\hline $40-49$ & 42 & 21.9 & 23 & 25.0 \\
\hline $50-59$ & 46 & 24.0 & 21 & 22.8 \\
\hline $60+$ & 36 & 18.7 & 14 & 15.2 \\
\hline \multicolumn{5}{|l|}{ Geographic location of residence } \\
\hline Northeast & 43 & 22.4 & 27 & 29.3 \\
\hline South & 58 & 30.2 & 30 & 32.6 \\
\hline Midwest & 47 & 24.5 & 16 & 17.4 \\
\hline West & 41 & 21.4 & 18 & 19.6 \\
\hline \multicolumn{5}{|c|}{ Credential, certification, degree, or licensure } \\
\hline RN/LVN & 1 & 0.5 & 1 & 1.1 \\
\hline Early childhood (special ed) & 14 & 7.3 & 4 & 4.3 \\
\hline Special education & 88 & 45.8 & 45 & 48.9 \\
\hline General education & 12 & 6.3 & 8 & 8.7 \\
\hline Both special \& general education & 59 & 30.7 & 29 & 31.5 \\
\hline Administrative & 6 & 3.1 & 2 & 2.2 \\
\hline Specialist & 12 & 6.3 & 3 & 3.3 \\
\hline \multicolumn{5}{|l|}{ Teaching experience (years) } \\
\hline $0-5$ & 37 & 19.3 & 15 & 16.3 \\
\hline $6-15$ & 51 & 26.6 & 25 & 27.2 \\
\hline $16-25$ & 44 & 22.9 & 24 & 26.1 \\
\hline $26-35$ & 42 & 21.9 & 21 & 22.8 \\
\hline $36+$ & 11 & 5.7 & 5 & 5.4 \\
\hline \multicolumn{5}{|c|}{ School district or service area student enrollment } \\
\hline $1-1,500$ & 36 & 21.3 & 21 & 26.6 \\
\hline $1,501-3,000$ & 17 & 10.1 & 9 & 11.4 \\
\hline $3,001-5,000$ & 22 & 13.0 & 8 & 10.1 \\
\hline $5,001-10,000$ & 14 & 8.3 & 9 & 11.4 \\
\hline $10,001-15,000$ & 10 & 5.9 & 4 & 5.1 \\
\hline $15,001-20,000$ & 14 & 8.3 & 5 & 6.3 \\
\hline $20,001+$ & 56 & 33.1 & 23 & 29.1 \\
\hline
\end{tabular}

Note. Specialist refers to those who may be psychologists, speech and language pathologists, etc. 


\section{The Status of Training to Provide Homebound Instruction}

Survey respondents were asked to specify whether they had received training, and if so, where the training occurred. The possible responses were: (a) a teacher preparation or certification program, (b) a school district or agency, or (c) a conference or workshop. Of the service provider responses, $19.8 \%(n=18)$ indicated they received training in a preparation or certification program; $25 \%(n=23)$ reported receiving training from a school district or agency; and $18.5 \%(n$ $=17)$ received training at a conference or workshop. The majority of service providers $(75 \%-$ $80 \%$ ) had not received training for delivering homebound instruction. Table 2 demonstrates the compilation of data. Six service providers indicated they received training from two sources.

Table 2

Homebound Instruction Service Provider Training

\begin{tabular}{|c|c|c|c|c|c|c|}
\hline \multirow[b]{2}{*}{ Training opportunity type } & \multicolumn{3}{|c|}{$\begin{array}{l}\text { All Participants } \\
(n=189)\end{array}$} & \multicolumn{3}{|c|}{$\begin{array}{l}\text { Service Providers } \\
\qquad(n=91)\end{array}$} \\
\hline & No & Yes & $\%$ Yes & No & Yes & $\%$ Yes \\
\hline Preparation/certification program & 156 & 33 & 17.2 & 73 & 18 & 19.8 \\
\hline School district/agency & 155 & 33 & 17.2 & 68 & 23 & 25.0 \\
\hline Conference/workshop & 157 & 32 & 16.7 & 74 & 17 & 18.5 \\
\hline
\end{tabular}

The survey also asked participants to report whether their agency or school district possessed resource materials such as guidelines, manuals, or handbooks pertaining to the delivery of homebound instruction. The majority of service providers $(66.7 \%)$ indicated their agencies or districts did not have these resources.

\section{Reported Services of Homebound Instruction}

Using survey responses, data were collected on the standard services and practices associated with homebound instruction. The most frequently reported settings for instruction outside of a K12 classroom were in the home $(54.3 \%)$ or a hospital $(22.8 \%)$. Reported caseloads ranged from one student per week (52.6\%) to five or more per week $(26.3 \%)$. Instructional sessions occurred most frequently twice per week (33.3\%) for a period of 60 to 89 minutes each (43\%). Survey participants reported the most frequent duration of service periods exceeded 16 weeks $(32.1 \%)$. Responses pertaining to the instructional setting, frequency, rate, and duration are represented in Table 3. 
Table 3

Setting, Frequency, Rate, and Duration of Typical Services

Instructional variables

$\%$

Location of instruction $(n=92)$

50

54.3

Hospital

21

22.8

Both student home and hospital

13

14.1

Community facility

4.3

Public facility

4

2.2

Other

2

2

2.2

Number of students instructed per week $(n=76)$

1

2

40

52.6

9

11.8

3

4

5.3

4

3.9

$5+$

26.3

Number of visits per student per week $(n=75)$

1

33.3

3

Instructional minutes per student per week $(n=79)$

$<30$

30-59

60-89

90-119

120-179

$>180$

$\begin{array}{rr}1 & 1.3 \\ 26 & 32.9 \\ 34 & 43.0 \\ 7 & 8.9 \\ 6 & 7.6 \\ 5 & 6.3\end{array}$

12

14

18

9

25
15.4

17.9

23.1

11.5

\section{Determinants for Homebound Instruction}

Determining the reasons students receive homebound instruction was another focus of this study. Surveys included possible reasons for homebound services and respondents were asked to designate the three most frequent reasons. Possible choices were: (a) serious or chronic illness; (b) short-term medical conditions such as illness or injury; (c) suspension; (d) expulsion; (e) waiting for alternative placements; (f) discipline for such violations as violence, bringing 
weapons to school, or drug possession; ( $\mathrm{g}$ ) behavior/mental health attributed to such conditions as a phobia or depression; and (h) being a pregnant minor. Respondents were also able to write in reasons not listed. In summary, medically-related causes were clearly the most frequent reasons accounting for the top two responses: serious or chronic illness $(44.6 \%)$; short-term medical condition (31.5\%); and discipline violation (7.6\%).

\section{Service Providers Perceptions of Effectiveness}

Statements in the survey measured service providers' perceptions of the effectiveness of homebound instruction as a service model and their perceptions of their personal effectiveness when delivering homebound instruction. Seven prompts measured service model effectiveness and six prompts measured personal effectiveness. Chronbach's alpha was used to measure internal consistency indicating satisfactory results for model effectiveness $(\alpha=.74)$ and good results for personal effectiveness $(\alpha=.85)$.

To establish whether there were significant differences in these variables between those who were trained and those who were not trained, an independent $t$-test was conducted. For model effectiveness, Levene's test for equality of variance showed no significant difference between the two groups $(F=.51, p=.48)$. Assuming equal variances, this independent test did not reach statistical significance, $t(86)=-1.98, p>.05$, however there was a medium effect size $(d=.43)$ with a marginally significant difference between those trained $(M=22.93, S D=4.82)$ and those not trained $(M=20.72, S D=5.58)$. For personal effectiveness, Levene's test showed no significant difference between the two groups $(F=.76, p=.39)$. Assuming equal variances, this independent test reached statistical significance, $t(86)=-2.73, p<.01$, and a medium effect size $(d=.59)$. The results of the $t$-test indicated there was a significant difference on perceptions of personal effectiveness between those trained $(M=26.02$, $S D=3.55)$ and those not trained $(M=$ $23.52, S D=4.88)$ but there were no significant statistical differences in the perceptions of model effectiveness (Table 4).

Multivariate analysis of variance (MANOVA) was used to examine the differences in the individual prompts for model effectiveness and personal effectiveness. For model effectiveness,

Table 4

Difference of Perceived Effectiveness between Not Trained and Trained Service Providers

\begin{tabular}{ccccc}
\hline Variables & $M$ & $S D$ & $t$ & $p$ \\
\hline Service model effectiveness & & & & \\
$\quad$ Not trained $(n=46)$ & 20.72 & 5.58 & -1.98 & 0.05 \\
Trained $(n=42)$ & 22.93 & 4.82 & & \\
Personal effectiveness & & & & 0.01 \\
Not trained $(n=46)$ & 23.52 & 4.88 & -2.73 & \\
Trained $(n=42)$ & 26.02 & 3.55 & & \\
\end{tabular}


there were no significant group differences amongst the prompts based on training or no training (Wilks' $\lambda=.92, F(7,77)=.91, p>.05$, multivariate $\eta^{2}=.08$ ), however for personal effectiveness, two of the prompts resulted in significant differences between trained and not trained service providers (Pillai's $T=.20, F(6,79)=3.32, p<.01$, multivariate $\eta^{2}=.20$ ). Pillai's Trace was used because the assumption for equal variances was violated for homogeneity of variance using Box's Test when evaluating personal effectiveness (Box's $M=62.38, F(21$, $25468)=2.74, p<.001)$. A medium effect size (partial $\left.\eta^{2}=.07\right)$ for the statement "I believe that I am effective when instructing homebound students" for those trained to provide homebound ( $M$ $=4.54, S D=.55)$ and for those not trained $(M=4.16, S D=.85)$ was indicated, while a large effect size (partial $\eta^{2}=.18$ ) for the statement "I believe I have been adequately trained to provide quality instruction," for those trained $(M=4.15, S D=.94)$ and not trained $(M=3.09, S D=1.31)$ resulted. In other words, those who had received training reported higher perceptions of personal effectiveness (Tables 5 and 6).

Table 5

Mean Scores and Standard Deviations for Measures of Perceptions of Personal Effectiveness based on Not Trained and Trained

\begin{tabular}{|c|c|c|c|c|c|c|c|c|c|c|c|c|}
\hline \multirow[b]{2}{*}{ Group } & \multicolumn{2}{|c|}{$\begin{array}{l}\text { I believe } \\
\text { I am } \\
\text { qualified }\end{array}$} & \multicolumn{2}{|c|}{$\begin{array}{l}\text { I believe } \\
\text { I am } \\
\text { effective }\end{array}$} & \multicolumn{2}{|c|}{$\begin{array}{l}\text { I believe } \\
\text { I have } \\
\text { adequate } \\
\text { training }\end{array}$} & \multicolumn{2}{|c|}{$\begin{array}{l}\text { I provide a } \\
\text { positive } \\
\text { experience } \\
\text { for students }\end{array}$} & \multicolumn{2}{|c|}{$\begin{array}{c}\text { I feel } \\
\text { personal } \\
\text { satisfaction }\end{array}$} & \multicolumn{2}{|c|}{$\begin{array}{l}\text { My efforts } \\
\text { to provide } \\
\text { quality are } \\
\text { successful }\end{array}$} \\
\hline & $M$ & $S D$ & $M$ & $S D$ & $M$ & $S D$ & $M$ & $S D$ & $M$ & $S D$ & $M$ & $S D$ \\
\hline $\begin{array}{l}\text { Not } \\
\text { trained }\end{array}$ & 4.00 & 1.09 & 4.16 & 0.85 & 3.09 & 1.31 & 4.40 & 0.69 & 4.11 & 1.03 & 4.09 & 0.95 \\
\hline Trained & 4.39 & 0.74 & 4.54 & 0.55 & 4.15 & 0.94 & 4.49 & 0.67 & 4.32 & 0.76 & 4.24 & 0.83 \\
\hline
\end{tabular}

Table 6

Post-hoc Univariate Analyses of Trained Service Providers Personal Effectiveness Perceptions

\begin{tabular}{lccc}
\hline \multicolumn{1}{c}{ Source } & $F$ & $p$ & $\eta^{2}$ \\
\hline I believe I am qualified & 3.72 & .057 & .042 \\
I believe I am effective & 5.93 & .017 & .066 \\
I believe I have adequate training & 18.19 & .000 & .178 \\
I provide a positive experience for students & 0.36 & .552 & .004 \\
I feel personal satisfaction & 1.10 & .297 & .013 \\
My efforts to provide quality are successful & 0.64 & .424 & .008 \\
\hline
\end{tabular}




\section{Discussion and Recommendations}

The provision of homebound services to students with disabilities is not a new practice; it dates back at least 50 years (Florida State Department of Education, 1983). Surprisingly, there is a paucity of information regarding the incidence of homebound services, trends in populations receiving such services, the training for its implementation, documented policies and procedures pertinent to homebound services, and the satisfaction related to such services. This study explored these variables.

Several implications and concerns became apparent during the review of available literature and the analysis of data from this study. One major concern was the availability of accurate incidence statistics concerning the placement of students with disabilities in homebound settings. Although the National Center for Educational Statistics (NCES; 2012) maintains an annual database of student placements, their statistics represent a snapshot during a finite period of time and as such do not reflect the potential for multiple placements throughout a given school year. This practice is particularly troubling since homebound instruction, as indicated in this study is typically shortterm rather than for an entire school year. Hence, the data from the NCES may not accurately represent the number of students who were serviced in homebound settings at some time during an annual report period. The practice of only identifying single placements at the time of data collection would be akin to measuring the rainfall for one week out of the year and using that information to represent the rainfall for the entire year. Not having accurate statistical data impacts perceptions of practitioners and policymakers concerning the prevalence of homebound services, populations receiving such services, as well as possible use and misuse of this placement option. The likely perception of homebound services being seldom utilized may marginalize their important functions.

Due to the expanded definition of interim alternative educational settings, there has been some concern regarding the inappropriate use of homebound services (Etscheidt, 2006; Lustig, 2009). The respondents to this study indicated that the primary reason their students received homebound instruction was because of medical issues such as serious, chronic, or short-term illness. These medically related reasons were indicated by almost $70 \%$ of the respondents. This is in keeping with estimations by the Journal of School Health (2003), which speculated that 10$15 \%$ of all school age children experience chronic illness and that a portion of these students with chronic illness would require homebound instruction. In addition to medically related reasons, respondents were able to specify whether homebound instruction was used as a consequence of suspension, expulsion, or for other behaviorally related issues (e.g., school phobia, violence, drugs). The data collected from this study demonstrated a relatively low use of homebound instruction for behavior or disciplinary related reasons. This is in contrast to concerns expressed by Etscheidt (2006) and Lustig (2009) who speculated about the potential for an increased use of homebound instruction as a disciplinary recourse. Based upon the results of this study, there is no evidence to suggest that homebound services have become dumping grounds for students with behavior problems, which have resulted from triggered automatic reactions rather than thoughtful placements.

Methods of delivering homebound instruction covered a wide range of options including the number, length and frequency of visits. Even though a wide range of options is available, the 
majority of the respondents expressed similar experiences. Most respondents indicated they commonly instructed one student at a time. Additionally, the instructional visits occurred two to three times weekly with each visit lasting between one and one and one-half hours. The duration of services most frequently covered an interval of 16 or more weeks. These findings are similar to those described in studies by Soles (1975) and Telzrow (2001).

The findings of this study confirmed the assertion by Patterson and Petit (2008) that there is a lack of training designed to prepare service providers in the delivery of homebound instruction. Approximately one-fourth of the respondents indicated that districts provided them with training, while less than $20 \%$ indicated that they received training from teacher preparation programs, or from professional development opportunities such as conferences or workshops. The results indicated that the majority of these service providers delivered services without benefit of having received any form of direct training concerning homebound services.

Another important finding from this study was that a majority of school districts do not appear to have written protocols available in the form of documented procedures, guidelines, handbooks, or manuals. Conversely, a majority of service providers reported that they were required to document their instructional sessions, take data on student progress, and report such information to administrators. The information gathered on these two seemingly opposing findings infers that there may be district or agency expectations regarding the delivery of homebound services, however, such expectations may be conveyed either verbally or in informal written fashion such as through emails or memorandums.

While few service providers reported that they had received direct training, the analysis of data from this study established that for those who did, the training positively impacted their perceptions on how effective they were when delivering homebound services. This statistically significant finding has bearing on the overall experience of homebound instruction. Those who were trained perceived themselves to be more effective.

The concept of teacher self-efficacy has been well researched since first introduced by Bandura in 1977 (de la Torre Cruz \& Casanova Arias, 2007). Teacher self-efficacy espouses the notion that teachers, who believe their instruction to be effective, do in fact, see growth in student learning. Correspondingly, teachers who doubt the efficacy of their instruction, see minimal student growth. Self-efficacy is developed through a variety of experiences including mastery experiences, physiological and emotional states, vicarious experiences, and social persuasion (Bandura, 1997). Direct training is an important factor in the development of self-efficacy. The results from this study parallel these assertions; survey respondents who received training in homebound delivery expressed higher degrees of personal effectiveness.

There are several important recommendations to be made as a consequence to the findings from this study. The first recommendation understandably concerns the training of homebound instructors. Because homebound instruction is administered through school districts or agencies, these entities are an appropriate starting point. Professional development offered at the agency, school district, or school site level could pinpoint the needs of students in homebound placements as well as echo district or agency policies concerning homebound services. Remembering that special education is a highly litigious field (Katsiyannis et al., 2001), districts 
and agencies do well to ensure that personnel are not only qualified but are also appropriately trained.

Teacher preparation programs at universities and colleges also have an obligation to equip special education teachers with the skills they will need to provide a continuum of services. Early childhood special education teacher preparation programs are more likely to provide training in conducting homebound instruction because of the emphasis on providing services in the natural environment (Klass, 2003). However, K-12 teachers may at some time in their careers be asked to provide homebound instruction even on a part-time or temporary basis. As such, teacher preparation programs must recognize the potential need for ensuring that candidates have, at the very least, an awareness level knowledge of the practices and approaches used for homebound instruction.

Furthermore, it is recommended that districts and agencies, minimally, develop and/or adopt written guidelines, manuals or handbooks. While not a substitute for training, written procedures and guidelines would establish a framework for the provision of homebound instruction. The written materials could address issues such as safety, documentation, lesson content, instructional strategies, and basic dos and don'ts. The wide use of technology affords districts and agencies a readily available medium to allow convenient online access to electronic documents, manuals, handbooks or guidelines.

The scarcity of empirical research in the area of homebound services remains a concern. Homebound services have been addressed peripherally in studies, but have rarely been the primary topic, particularly for students in grades K-12. Since homebound services appear to occur on a relatively infrequent basis, finding respondents who have instructed in a homebound setting can be problematic. This study relied on two professional organizations for respondents, however, there is a strong possibility that the majority of special education teachers and related service providers do not belong to professional organizations and were therefore not within the study respondent pool. Future research would benefit from a larger respondent pool, especially one that includes better representation from related service providers. Moreover, the researchers of this study recognize the value that qualitative research could contribute greatly to the understanding and improvement of homebound services. The investigation through qualitative approaches of the rich, personal experiences of service providers who may detail unanticipated practices, factors, and variables stands to benefit students who receive instruction in a homebound setting by informing the community that provides these services.

\section{Conclusion}

IDEIA (2004) provides for a continuum of placements as well as the use of interim alternative educational settings. Homebound instruction can be a primary as well as interim placement. In either instance, school districts are obligated to provide appropriate educational services for students. Appropriate instruction is not limited to the use of the least restrictive environment but also encompasses suitable instruction by a qualified and trained service provider. Results from this study may be cause for speculation that due to the low-incidence nature of this service model, the provision of homebound instruction is often administered in a less than formal manner. Although homebound instruction is often provided as an interim placement, students receiving these services are nonetheless entitled to a well-structured, instructionally sound, and accountable program. 


\section{References}

American Academy of Pediatrics, Committee on School Health. (2000). Home, hospital, and other non-school-based instruction for children and adolescents who are medically unable to attend school. Pediatrics, 106(5), 1154-1155. http://dx.doi.org/10.1542/peds.106.5.1154

Bandura, A. (1997). Self-efficacy: The exercise of control. New York: W. H. Freeman \& Company.

Bear, G. G., Quinn, M. M., \& Burkholder, S. (2001). Interim alternative educational settings for children with disabilities. Bethesda, MD: National Association of School Psychologists.

Boreson, L. (1994). A programming guide for emotional disturbance. Madison, WI: Wisconsin State Department of Public Instruction.

Bradley, R. (2007). Key issues in discipline. In Building the Legacy: IDEA 2004 Training Curriculum (module 19). Retrieved from the National Dissemination Center for Children with Disabilities website: http://www.parentcenterhub.org/repository/partb-module19/

Clay, D.L., Cortina, S., Harper, D.C., Cocco, K.M., \& Drotar, D. (2004). Schoolteachers' experiences with childhood chronic illness. Children's Health Care, 33(3), 227- 239. http://dx.doi.org/10.1207/s15326888chc3303_5

Cook, R., Sparks, S., Rosetti, L., \& Osselaer, C. (2008). The art and practice of home visiting: Early intervention for children with special needs and their families. Baltimore, MD: Paul H. Brooks Publishing Co.

Data Accountability Center. (2012). Individuals with disabilities education act (IDEA) data. Retrieved from the Office of Special Education Programs, U.S. Department of Education website: http://www.ideadata.org

de la Torre Cruz, M. J., \& Casonova Arias, P. F. (2007). Comparative analysis of expectancies of efficacy in in-service and prospective teachers. Teaching and Teacher Education: An International Journal of Research and Studies, 23(5), 641-652. http://dx.doi.org/10.1016/j.tate.2007.02.005

Dillman, D.A., Smyth, J.D., \& Christian, L.M. (2009). Internet, mail, and mixed mode survey: The tailored design method (3rd ed.). Hoboken, NJ: Wiley.

Etscheidt, S. (2006). Seeking and an interim alternative education placement for dangerous or disruptive students with disabilities: Four burdens for the school district to meet. American Secondary Education, 34(2), 67-84.

Florida State Department of Education. (1983). A training manual for teachers of the homebound/hospitalized student (Vol. IV-B, in A resource manual for the development and evaluation of special programs for exceptional students). Tallahassee, FL: Author. 
Hamlet, H.S., Gergar, P.G., \& Schaefer, B.A. (2011). Students living with chronic illness: The school counselor's role. Professional School Counseling, 14(3), 202-210. http://dx.doi.org/10.5330/PSC.n.2011-14.202

Individuals With Disabilities Education Act, 20 U.S.C. § 1400 (2004).

Johnson, B., \& Christensen, L. (2008). Educational research: Quantitative, qualitative, and mixed approaches $\left(3^{\text {rd }}\right.$ ed.). Thousand Oaks, CA: Sage Publications.

Journal of School Health. (2003). Students with chronic illness: Guidance for families, schools, and students. Journal of School Health, 73(4), 131-132. http://dx.doi.org/10.1111/j.17461561.2003.tb03588.x

Katsiyannis, A., \& Smith, C. R. (2003). Disciplining students with disabilities: Legal trends and the issue of interim alternative education settings. Behavioral Disorders, 28(4), 410-418.

Katsiyannis, A., Yell, M. L., \& Bradley, R. (2001). Reflections on the 25th anniversary of the Individuals with Disabilities Education Act. Remedial and Special Education, 22(6), 324334. http://dx.doi.org/10.1177/074193250102200602

Keilty, B. (2008). Early intervention home-visiting principles in practice: A reflective approach. Young Exceptional Children, 11(2), 29-40. http://dx.doi.org/10.1177/1096250607311933

Klass, C. S. (2003). The home visitor's guidebook: Promoting optimal parent \& child development ( $2^{\text {nd }}$ ed.). Baltimore: Paul H. Brookes.

Krathwohl, D. R. (2009). Methods of educational and social science research: The logic of methods $\left(3^{\text {rd }}\right.$ ed.). Long Grove, IL: Waveland Press, Inc.

Lustig, B. C. (2009). Homebound instruction: The legal segregation of students with disabilities under the Individuals with Disabilities Education Act (Doctoral dissertation). Retrieved from ProQuest Dissertations and Theses database. (UMI No. 3373920).

Macciomei, N. R., \& Ruben, D. H. (1989). Homebound teaching: A handbook for educators. Jefferson, NC: McFarland \& Company, Inc.

National Center for Educational Statistics. (2012). Digest of education statistics. Retrieved from http://nces.ed.gov/programs/digest/

North Carolina Association for the Education of Chronically Ill Children. (2009). NCAECIC research committee report on homebound instruction survey of neighboring states. Retrieved from http://www.ncaecic.org/Homebound-Instruction.php

Patterson, P. P., \& Petit, C. (2006). Helping to make homebound instruction successful. The Exceptional Parent, 36(9), 44-46. 
Patterson, P. P., \& Petit, C. (2008). Teaching homebound children. National Association of Elementary School Principals, 87(3). Retrieved from www.naesp.org

Patterson, P. P., \& Tullis, L. (2007). Guidelines for providing homebound instruction to students with disabilities. Preventing School Failure, 51(2), 29-33. http://dx.doi.org/10.3200/PSFL.51.2.29-33

Petit, C. C. (2013). The usage of homebound instruction: Training, preparation, and perceptions of service providers. (Doctoral dissertation). Available from ProQuest Dissertations and Theses database. (UMI No. 3567874).

Prior, J., \& Gerard, M. R. (2007). Family involvement in early childhood education: Research into practice. Clifton Park, NY: Thompson Delmar Learning.

Scarborough, A. A., Spiker, D., Mallik, S., Hebbeler, K. M., Bailey, D. B., \& Simeonsson, R. J. (2004). A national look at children and families entering early intervention. Exceptional Children, 70(4), 469-483.

Searle, N. S., Askins, M., \& Bleyer, W. A. (2003). Homebound schooling is the least favorable option for continued education of adolescent cancer patients: A preliminary report. Medical and Pediatric Oncology, 40, 380-384. http://dx.doi.org/10.1002/mpo.10270

Shaw, S. R., Glasner, S. E., Stern, M., Sferdenschi, C., \& McCabe, P. C. (2010). Responding to students' chronic illnesses. Principal Leadership, 10(7), 12-16.

Shaw, S. R., \& McCabe, P. C. (2008). Hospital-to-school transition for children with chronic illness: Meeting the new challenges of an evolving health care system. Psychology in the Schools, 45(1), 74-87. http://dx.doi.org/10.1002/pits.20280

Soles, S. (1975). Remedial program in reading and mathematics for homebound children. Brooklyn, NY: New York City Board of Education.

Special Education \& Rehabilitative Services. (2007). Archived: A 25 year history of the IDEA. U.S. Department of Education. Retrieved from http://www.ed.gov/policy/speced/leg/idea/history.html

Telzrow, C. F. (2001). Interim alternative educational settings school district implementation of IDEA 1997 requirements. Education and Treatment of Children, 24(1), 72-98.

U.S. Department of Education (2013). Building the legacy: IDEA 2004. Retrieved from http://idea.ed.gov 